\title{
Molecular characterization and developmental expression patterns of thyroid hormone receptors (TRs) and their responsiveness to $T R$ agonist and antagonist in Rana nigromaculata
}

\author{
Qinqin Lou ${ }^{1,2}$, Yinfeng Zhang ${ }^{1}$, Dongkai Ren ${ }^{1}$, Haiming Xu' ${ }^{1}$, Yaxian Zhao', \\ Zhanfen Qin ${ }^{1, *}$, Wuji Wei ${ }^{2, *}$ \\ 1. State Key Laboratory of Environmental Chemistry and Ecotoxicology, Research Center for Eco-environmental Sciences, \\ Chinese Academy of Sciences, Beijing 100085, China. E-mail: louqinqindy@163.com \\ 2. College of Environment, Nanjing University of Technology, Nanjing 210009, China
}

\section{A R T I C L E I N F O}

Article history:

Received 5 November 2013

Revised 5 March 2014

Accepted 3 April 2014

Available online 11 August 2014

\section{Keywords:}

Rana nigromaculata

Thyroid hormone receptor

Thyroid hormone signaling

Developmental expression pattern

Responsiveness

\begin{abstract}
A B S T R A C T
Considering some advantages of Rana nigromaculata as an experimental species, we propose that this species, like Xenopus laevis, could be used to assay thyroid hormone (TH) signaling disrupting actions. To validate the utilizability of $R$. nigromaculata, we investigated the responsiveness of $R$. nigromaculata to a TH receptor (TR) agonist (T3) and antagonist (amiodarone) by analyzing expression, based on characterizing TR CDNA and developmental expression patterns. With high levels of identity with the corresponding genes in X. laevis, both TR $\alpha$ and TR $\beta$ in R. nigromaculata exhibited roughly similar developmental expression patterns to those of X. laevis, in spite of some species-specific differences. Both TR $\alpha$ and TR $\beta$ expression had greater changes in the liver and intestine than in the tail and brain during metamorphosis. T3 exposure for 2 days induced more dramatic increases of TR $\beta$ expression in stage 27 than in stage 34 tadpoles but not in stage 42 tadpoles, showing that the responsiveness of $R$. nigromaculata to $\mathrm{TH}$ decreased with development and disappeared at the onset of metamorphic climax. Corresponding to greater changes of TR $\beta$ expression in the liver and intestine than in the tail and brain during metamorphosis, the liver and intestine had higher responsiveness to exogenous T3 than the tail and brain. Amiodarone inhibited T3-induced TR $\beta$ expression. Our results show that $R$. nigromaculata can be used as a model species for assaying TH signaling disrupting actions by analyzing TR $\beta$ expression, and intestine tissues at stage 27 are ideal test materials due to high responsiveness and easy accessibility.
\end{abstract}

(C) 2014 The Research Center for Eco-Environmental Sciences, Chinese Academy of Sciences. Published by Elsevier B.V.

\section{Introduction}

Thyroid hormones (THs, $\mathrm{T} 3$ and $\mathrm{T} 4$ ) are involved in a wide range of biological processes associated with development, metabolism, growth and reproduction in vertebrates. THs are regulated by the hypothalamic-pituitary-thyroid (HPT) axis, and their actions are mainly mediated through transcriptional regulation by TH receptors (TRs, TR $\alpha$ and TR $\beta$ ) (Yen, 2001; Bernal et al., 2003). In the past decades, some chemicals have been found to disrupt the complex thyroid system via various pathways in animals (Brucker-Davis, 1998; Zoeller, 2007). Epidemiological data suggest that chemical pollutants may be associated with human thyroid imbalance

\footnotetext{
* Corresponding author. E-mails: qinzhanfen@rcees.ac.cn (Zhanfen Qin); wjwei@njut.edu.cn (Wuji Wei).
} 
(Langer et al., 2007). Because amphibian metamorphosis is controlled by THs, amphibian metamorphosis provides a unique biological model for studying thyroid disruptors, based on the potential utility of morphological and molecular markers of metamorphosis as endpoints of thyroid status in the developing tadpoles (Tata, 2006; Heimeier et al., 2010; Das et al., 2010). The Amphibian Metamorphosis Assay developed by OECD (2009) has been applied to screen thyroid disruptors that may interfere with the normal functioning of the HPT axis (Carr and Patino, 2011; Gutleb et al., 2007). In addition, TH-induced metamorphosis is also used to identify thyroid disruptors that may bind to TRs and alter TH actions and signaling (Heimeier et al., 2009; Helbing et al., 2006). TH-dependent gene expression and morphological changes induced by $\mathrm{TH}$ are regarded as good endpoints for evaluating TH signaling disrupting effects of chemicals (Heimeier et al., 2009; Helbing et al., 2006; Fini et al., 2012). In particular, TH-induced expression of TRs (especially TR $\beta$ ) has been used as a molecular biomarker for evaluating $\mathrm{TH}$ signaling disrupting effects in amphibians (Opitz et al., 2006; Veldhoen et al., 2006a, b).

In the literature, Xenopus laevis is the most-used model species for studying thyroid disrupting effects (Degitz et al., 2005; Heimeier et al., 2009). Given the obtainability of experimental animals, some native amphibian species, such as Rana catesbeiana and Rana pipiens (Helbing et al., 2006; Croteau et al., 2009), Rana temporaria (Arukwe and Jenssen, 2005; Gutleb et al., 2000) and Rana rugosa (Hanada et al., 2003; Oka et al., 2009), are used to assess effects of chemicals on the thyroid system. Rana nigromaculata (Pelophylax nigromaculatus) is a species of true frog distributed in East Asia. R. nigromaculata has been used in toxicological studies (Li et al., 2009; Wang and Jia, 2009) as well as biological studies (Park et al., 2001; Sumida et al., 2001, 2004; Takase et al., 2002). R. nigromaculata has some advantages as an experimental species. For example, R. nigromaculata tadpoles as well as frogs are maintained easily in the laboratory, and metamorphose into frogs approximately 7 weeks postfertilization. It is noteworthy that the natural death rate of $R$. nigromaculata tadpoles is very low, even close to zero. The relatively short generation time (one year) also provides a good reason for use of $R$. nigromaculata as an experimental species. Importantly, R. nigromaculata can be induced to breed by injecting luteinizing hormone releasing hormone (LHRH) and human chorionic gonadotropin (HCG) accompanied by simulating rainfall. Given the above advantages, we propose that $R$. nigromaculata could be a good experimental species for assaying thyroid disruptors.

To develop $R$. nigromaculata as a native model species for assaying TH signaling disrupting effects of chemicals, it is necessary to characterize TR CDNA, describe its developmental expression patterns and evaluate responsiveness to TR agonist/antagonists in R. nigromaculata. In this study, we aimed to obtain information on TR in R. nigromaculata to validate the utilizability of R. nigromaculata as a model species for assaying TH signaling disrupting effects.

\section{Materials and methods}

\subsection{Animals and sampling}

Initially, adult frogs were obtained from a $R$. nigromaculata farm in Bengbu, Anhui Province, China. Two generations were bred in our amphibian house. R. nigromaculata frogs were raised in glass tanks, in which dechlorinated water and a layer of scree constituted the amphibious environment, and fed with Terzebrio molitor daily. Breeding were induced by injecting $15 \mu \mathrm{g}$ LHRH (Ningbo second hormone factory, Zhejiang, China) and human chorionic gonadotropin (HCG, Yantai North Pharmaceutical Co. Ltd., Shandong, China; 300 IU for female and $200 \mathrm{IU}$ for male) dissolved in $0.6 \% \mathrm{NaCl}$, accompanied by simulating rainfall. Fertilized eggs were incubated in dechlorinated tap water and developed into tadpoles on the 5 th day postfertilization. The tadpoles were transferred into tadpole tanks $(100 \mathrm{~cm} \times 60 \mathrm{~cm} \times 30 \mathrm{~cm})$ with a water depth of $15 \mathrm{~cm}$ and fed with commercial diets (Totoro Supplies, Hong Kong, China) twice daily. The density of tadpoles in water was less than 5 tadpoles/L before Gosner stage 30 (1960); later, less than 1.5 tadpoles/L. The water was changed twice per week. The water quality for raising $R$. nigromaculata was as follows: without chlorine, $\mathrm{pH}$ 6.5-7, dissolved oxygen concentration $>5 \mathrm{mg} / \mathrm{L}$, and water hardness $\left(\mathrm{CaCO}_{3}\right)$ approximately $150 \mathrm{mg} / \mathrm{L}$. In the amphibian house $\left(23 \pm 2^{\circ} \mathrm{C}\right)$, fluorescent lighting provided a photoperiod of $12 \mathrm{hr}$ light:12 hr dark with a light intensity ranging from 600 to $1000 \mathrm{~lx}$ at the water surface for tadpoles and ranging 100 to $300 \mathrm{~lx}$ for frogs. The tadpoles completed metamorphosis within approximately 7 weeks postfertilization.

The developmental stages of $R$. nigromaculata were determined according to the Gosner system (Gosner, 1960). After anesthetization of the frogs (six months) by immersion in 3-aminobenzoic acid ethyl ester (MS222, Sigma-Aldrich; $1 \mathrm{~g} / \mathrm{L}$ in water), brain tissues were collected to extract RNA for cloning and sequencing of TR cDNA. For TR mRNA expression analysis, the tissues of brain, liver, intestine, and tail were freshly sampled from the tadpoles at different stages after anesthetization by MS222. Tissue samples were frozen immediately in liquid nitrogen, followed by storage at $-80^{\circ} \mathrm{C}$ until RNA extraction. All animal procedures were conducted according to Regulations for the Administration of Affairs Concerning Experimental Animals (State Science and Technology Commission of the People's Republic of China, 1988).

\subsection{Cloning and molecular characterization of TR genes in R. nigromaculata}

\subsubsection{RNA extraction and reverse transcription}

Total RNA was extracted using TRIzol reagent (Invitrogen, Shanghai, China), following the manufacturer's instructions. Total RNA concentration was calculated from absorbance at 260 nm (Nanodrop ND-1000, Nanodrop, USA), and RNA quality was verified by electrophoresis on ethidium-bromide-stained $1 \%$ agarose gels and by $A_{260} \mathrm{~nm} / \mathrm{A}_{280 \mathrm{~nm}}$ ratios in the range of 1.82.0. Then the RNA was reverse transcribed into cDNA using SuperScriptIII reverse transcriptase (Invitrogen, Shanghai, China), following the manufacturer's instructions.

\subsubsection{Cloning and sequencing of TR genes}

Full-length TR $\alpha$ and TR $\beta$ cDNA sequences were generated by reverse transcriptase polymerase chain reaction (RT-PCR) and rapid amplification of CDNA ends (RACE). The partial fragments of TR $\alpha$ and TR $\beta$ CDNA were obtained by RT-PCR. The primers of $\mathrm{TR} \alpha$ and TR $\beta$ were designed according to the corresponding sequences of R. catesbeiana (L06064.1 and L27344.1), R. rugosa (AB683466.1 and AB683467.1) and R. pipiens (DQ398026.1 and AY049025.1) in the NCBI GenBank database (Table 1). The PCR products were sequenced by Invitrogen Corporation (Shanghai, China). To obtain the $3^{\prime}$ end and 5' end sequences of TR $\alpha$ and TR $\beta$ genes, nested rapid amplification of CDNA end PCR was performed using the GeneRacer Kit (Invitrogen, Shanghai, China) according to the manufacturer's instructions. On the 
Table 1 - Primers used for rapid amplification of cDNA ends (RACE) and quantitative RT-PCR (qRT-PCR).

\begin{tabular}{|c|c|}
\hline Primer & Sequence \\
\hline \multicolumn{2}{|c|}{ Primers for partial fragment } \\
\hline $\mathrm{TR} \alpha-\mathrm{F}$ & 5'-TTCAGCGAGTTTACCAAGATCATCAC-3' \\
\hline $\mathrm{TR} \alpha-\mathrm{R}$ & 5'-TTAGACTTCCTGATCCTCAAAGACCTC-3' \\
\hline TR $\beta$-F & 5'-AGCAGCATGTCAGGGTAC-3' \\
\hline $\mathrm{TR} \beta-\mathrm{R}$ & 5'-TGAAGGCTTCTAAGTCCA-3' \\
\hline \multicolumn{2}{|c|}{ Primers for 3'-RACE PCR } \\
\hline TR $\alpha-3^{\prime} G S P 1$ & 5'-CGAACGGGTTTGATCTGCACAGATAA-3' \\
\hline TR $\alpha-3^{\prime} G S P 2$ & 5'-AAATCATCGCAAACACAACATTCCCC-3' \\
\hline TR $\beta$-3'GSP1 & 5'-GCGTGGTGTGTGGAGACAAGGC-3' \\
\hline TR $\beta-3^{\prime}$ GSP2 & 5'-ACTGTGCGTGGTGTGTGGAGA-3' \\
\hline \multicolumn{2}{|c|}{ Primers for 5'-RACE PCR } \\
\hline$T R \alpha-5^{\prime} G S P 1$ & 5'-GCCACTTCCGTGTCATCCAGATTGAAC-3' \\
\hline TR $\alpha-5^{\prime} G S P 2$ & 5'-TCCACCATTCTTCAGCTGTTCTCGCTT-3' \\
\hline TR $\beta-5^{\prime}$ GSP1 & 5'-GCTGGCATGGCAGGCTCCAA-3' \\
\hline TR $\beta-5^{\prime} G S P 2$ & 5'-AGTCCACTTTTCCACCCTCCGGT-3' \\
\hline \multicolumn{2}{|c|}{ Primers for full-length PCR } \\
\hline $\mathrm{TR} \alpha-\mathrm{F}$ & 5'-GACCAGAATCTTAGCGGGCTG-3' \\
\hline$T R \alpha-R$ & 5'-GGGAGCAAGAGAACTTTCAGTC-3' \\
\hline TR $\beta$-F & 5'-ATGCCTAGCAGCATGTCA-3' \\
\hline $\mathrm{TR} \beta-\mathrm{R}$ & 5'-AAAGAAGCACAGTCTCTTC-3' \\
\hline \multicolumn{2}{|c|}{ Primers for quantitative real-time PCR } \\
\hline$T R \alpha-F$ & 5'-TCTCCGGGCTGCTGTGCGTTA-3' \\
\hline $\mathrm{TR} \alpha-\mathrm{R}$ & 5'-GCATCTGAGACCACCCCAAGTCCA-3' \\
\hline TR $\beta$-F & 5'-GCTAGATGACTGTGCGTGGT-3' \\
\hline $\mathrm{TR} \beta-\mathrm{R}$ & 5'-ACAGGAATAGCTTGGGTGAAGA-3' \\
\hline rpl8-F & 5'-GCTGTCGACTTCGCAGAAAGGCA-3' \\
\hline rpl8-R & 5'-ACCTGTAAGGGTCACGGAAGGCA-3' \\
\hline
\end{tabular}

basis of the partial fragment sequences of TR $\alpha$ and TR $\beta$, two pairs of gene specific primer (GSP) were designed for $3^{\prime}$-RACE and $5^{\prime}$-RACE of TR genes, respectively (Table 1). The RACE PCR products of TRs were purified by ethidium bromide gel electrophoresis. The gel-purified products were cloned into the $\mathrm{PCR} \circledast 4$-TOPO ${ }^{\circledR}$ plasmid using the TOPO TA Cloning® for Sequencing Kit (Invitrogen, Shanghai, China). The nucleotide sequences of TR $\alpha$ and TR $\beta$ were determined by Sanger sequencing (Invitrogen, Shanghai, China). To obtain the complete coding region of $T R \alpha$ and TR $\beta$, two pairs of full-length primers were designed based on the RACE sequencing results (Table 1).

\subsubsection{Sequence analysis and phylogenetic analysis}

The cDNA sequence and deduced amino acid sequence were analyzed using Blastn and Blastp, respectively. The open reading frame was found by ORF Finder in NCBI (www.ncbi. nlm.nih.gov). The sequence alignments were carried out using CLUSTAL X. Phylogenetic analysis was conducted with MEGA4 and the phylogenetic tree was drawn using the Neighbor-Joining method. The sequences of TR $\alpha$ and TR $\beta$ in some species were from the NCBI GenBank database.

\subsection{Expression patterns of TRs during R. nigromaculata development}

For TR mRNA expression analysis in various tissues during R. nigromaculata development, we conducted quantitative real-time PCR (qRT-PCR) using SYBR Green I with the MX Real-time Polymerase Chain Reaction system (Stratagene
MX3005P, Agilent, USA). Specific primers of TR $\alpha$ and TR $\beta$ were designed according to the corresponding cDNA sequences obtained by RACE (Table 1). Ribosomal protein L8 (rpl8) was used as a reference gene to normalize mRNA expression of TRs, because its stable expression during $R$. nigromaculata development and low tissue-specificity has been demonstrated in our previous study (Lou et al., 2014). Specific primers for rpl8 are shown in Table 1. PCR conditions were as follows: $95^{\circ} \mathrm{C}$ for $2 \mathrm{~min}, 40 \mathrm{cycles}$ at $95^{\circ} \mathrm{C}$ for $20 \mathrm{sec}, 60^{\circ} \mathrm{C}$ (TR $\alpha$ and rpl 8 ) or $63^{\circ} \mathrm{C}(\mathrm{TR} \beta)$ for $30 \mathrm{sec}$, and $68^{\circ} \mathrm{C}$ for $30 \mathrm{sec}$, followed by a melting curve analysis.

\subsection{Responsiveness of $R$. nigromaculata to exogenous TR agonist and antagonist}

R. nigromaculata tadpoles at Gosner stages 27 (pre-metamorphic stage), 34 (early pro-metamorphic stage), and 42 (metamorphic climax stage) were exposed to TR agonist T3 (1 nmol/L) in glass tanks $(500 \mathrm{~mL}$ ) with $400 \mathrm{~mL}$ of dechlorinated water. A blank control for each stage was set. Two replicate test tanks (5 tadpoles per tank) were employed for each treatment group. T3 replacement was performed every $24 \mathrm{hr}$ following water changes. The tadpoles were not fed during the exposure period. The housing conditions were as described above. After exposure for $48 \mathrm{hr}$, the liver, brain, intestine and tail tissues of tadpoles were collected for RNA extraction. TR $\alpha$ and TR $\beta$ expression levels were examined by qRT-PCR according to the methods described above.

By comparing the responsiveness of tadpole tissues to T3, we chose tissues from the most sensitive stage as test materials. The tadpoles were exposed to a series of concentrations of TR antagonist amiodarone (AM) in the presence of $0.1 \mathrm{nmol} / \mathrm{L}$ T3 or in the absence of T3. Two replicate test tanks ( 5 tadpoles per tank) were employed for each treatment group. Exposure conditions were as described above. After exposure for $48 \mathrm{hr}$, the liver, brain, intestine and tail tissues of tadpoles were collected for RNA isolation. TR $\alpha$ and TR $\beta$ expression levels were examined by qRT-PCR according to the methods described above.

\subsection{Statistical analysis}

Statistical analysis was performed using SPSS software version 16.0 (SPSS, IBM, Chicago, USA). Quantitative data were shown as mean $\pm \mathrm{SD}$. The fold change of TRs expression in a specific stage or tissue was determined by $2^{-\Delta \Delta C t}$ (cycle threshold, Ct). Statistical difference in mRNA expression between tissues was assessed by one-way analysis of variance and independent-sample $\mathrm{T}$ test. A $p<0.05$ was regarded as significant.

\section{Results}

\subsection{Molecular characterization of $\operatorname{TR} \alpha$ and $\operatorname{TR} \beta$ CDNA in R. nigromaculata}

The cDNA sequences of $\operatorname{TR} \alpha$ and $\operatorname{TR} \beta$ were obtained using RT-PCR and 5'-/3'-RACE strategies. Two sequences were submitted to the GenBank (GenBank accession numbers: 
KC139354, KC139355). The TR $\alpha$ cDNA was a transcript of $1760 \mathrm{bp}$ that contained an open reading frame (ORF) of $1256 \mathrm{bp}$ from 16 to $1272 \mathrm{bp}$, which encoded a peptide of 418 amino acids. The TR $\beta$ cDNA was a transcript of $1152 \mathrm{bp}$ that contained an ORF of $1122 \mathrm{bp}$ from 1 to $1122 \mathrm{bp}$, which encoded a peptide of 373 amino acids. The homologies of nucleotide
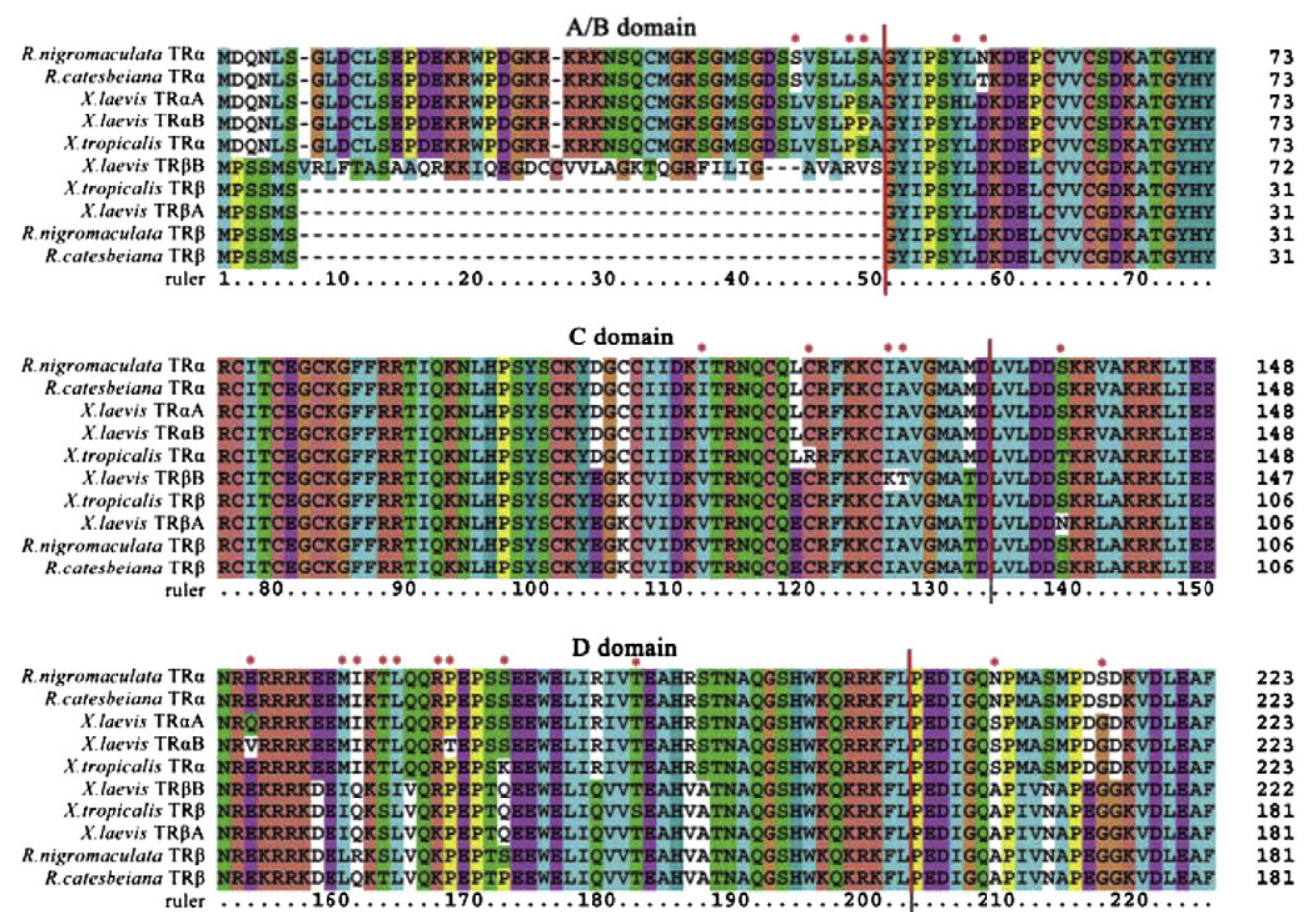

E/F domain
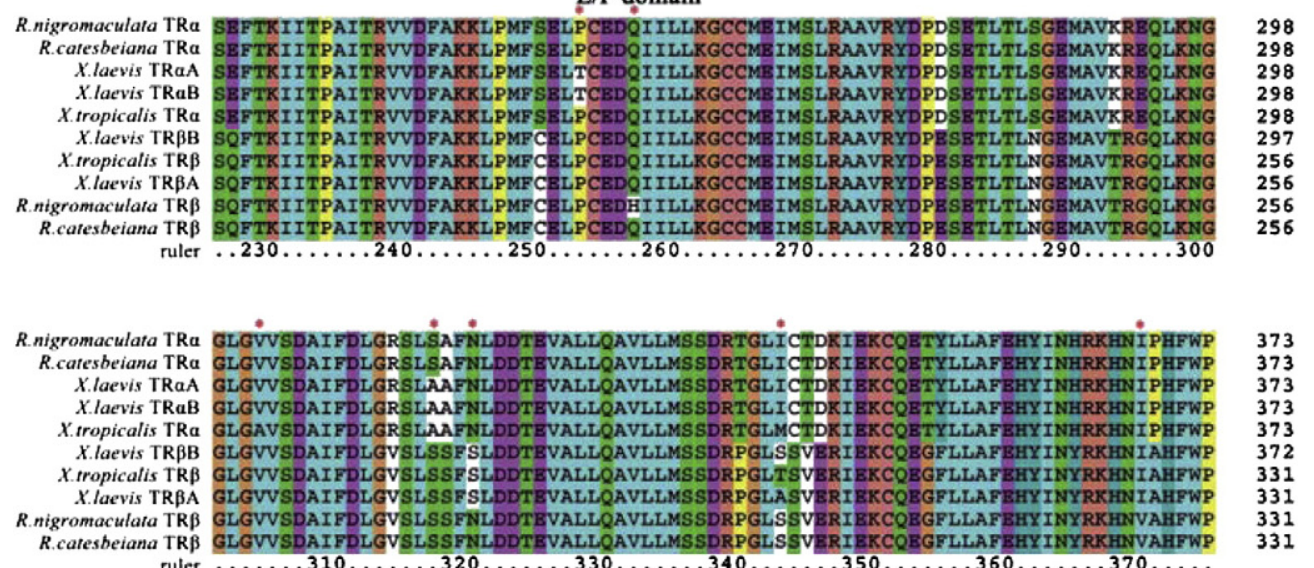

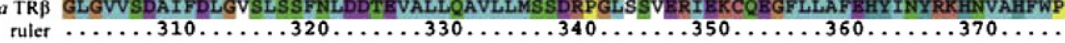
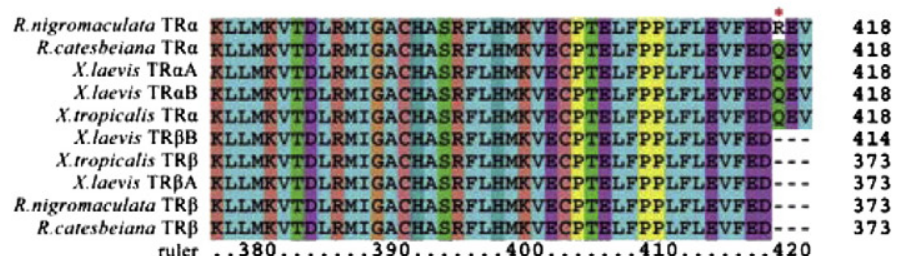

Fig. 1 - Alignments of the amino acid sequences of TRs between Rana nigromaculata and other amphibian species. The relevant amino acid sequences were obtained from the NCBI GenBank database: Rana catesbeiana (Q02777.1, Q02965.1), Xenopus laevis (NP_001081595.1, BAL70322.1, NP_001090182.1, NP_001081250.1), Xenopus tropicalis (NP_001039261.1, NP_001039270.1).The red vertical lines indicate the borders of four domains: the $\mathrm{N}$-terminal hypervariable region (A/B domain), DNA-binding domain (C domain), hinge region (D domain) and hormone-binding domain (E/F domain). Hyphens denote that the bases are gaps with those in the top line. Red asterisk marks the diversity of TR $\alpha$ and TR $\beta$ between Rana nigromaculata and Rana catesbeiana and Xenopus laevis. 
sequences and deduced amino acid sequences between TR $\alpha$ and TR $\beta$ in R. nigromaculata were $72 \%$ and $86 \%$, respectively.

A multiple alignment of TR-deduced amino acid sequences was performed in amphibians (Fig. 1). The deduced amino acids of both TR $\alpha$ and TR $\beta$ were composed of the N-terminal hypervariable region (A/B domain), DNA-binding domain (C domain), hinge region ( $D$ domain) and hormone-binding domain (E/F domain). TR $\alpha$ and $T R \beta$ in $R$. nigromaculata had high similarity in the DNA-binding domain, hinge region and hormone-binding domain, whereas there was a deletion of 42 amino acids in TR $\beta$ compared with TR $\alpha$ in the $A / B$ domain. In addition, 51 amino acids were different between TR $\alpha$ and TR $\beta$ in C, D and E/F domains (Fig. 1). These differences between $\mathrm{TR} \alpha$ and $\operatorname{TR} \beta$ in $R$. nigromaculata corresponded to the differences found in X. laevis, Xenopus tropicalis and R. catesbeiana.

$T R \alpha$ and TR $\beta$ in $R$. nigromaculata resembled their counterparts in reptiles, birds, mammals and other amphibian species (Table 2). Phylogenetic analysis by the Neighbor-Joining tree revealed the phylogenetic relationship of TR $\alpha$ and TR $\beta$ between R. nigromaculata and other species (Fig. 2). The amino acid sequences of $R$. nigromaculata $T R \alpha$ had high identity with $X$. laevis TR $\alpha \mathrm{A}(98 \%, 10$ different sites out of 418 amino acids) and $X$. laevis $\mathrm{TR} \alpha \mathrm{B}$ (98\% homology, 10 different sites out of 418 amino acids). The amino acid sequence identity of TR $\alpha$ between $R$. nigromaculata and $R$. catesbeiana even reached $99 \%$, with only 2 different sites among 418 amino acids. The amino acid sequence of $R$. nigromaculata TR $\beta$ had $98 \%$ and $96 \%$ identity values with $X$. laevis TR $\beta A$ and TR $\beta B$, respectively. In accordance with the high homology of TR $\alpha$, only 4 of 373 amino acids of TR $\beta$ were different between R. nigromaculata and R. catesbeiana.

\subsection{TR expression patterns during metamorphic development}

Expression of $T R \alpha$ and $T R \beta$ was detectable in the liver, intestine, tail and brain of R. nigromaculata at Gosner stage 27-46 (Fig. 3). In the liver, the mRNA levels of TR $\alpha$ increased gradually from stage 27, peaked at stage 42 (forelimb breaking through operculum), and then reduced dramatically toward stage 46 (the end of metamorphosis). In the intestine and tail, however, $\mathrm{TR} \alpha$ expression remained at relatively low and constant levels before stage 40 , whereas it started to increase dramatically at stage 40 , and peaked rapidly at stage 42 , followed by a dramatic decrease toward the end of metamorphosis. Notably different from the above tissues, TR $\alpha$ expression was maintained at a high level in the brain and only exhibited a weak increasing trend from stage 27 to stage 41, followed by a slight decrease toward the end of metamorphosis.

In all tissues examined, TR $\beta$ expression was low and relatively constant before stage 40 , began to increase at stage 40 , and peaked rapidly at stage 42 . Then, the TR $\beta$ mRNA levels reduced rapidly toward the end of metamorphosis, especially dramatically in the intestine and tail. At the end of metamorphosis, TR $\beta$ expression in the intestine and tail almost declined to the levels observed before stage 40, whereas TR $\beta$ expression in the liver and brain maintained higher levels than those before stage 40 .

Overall, TR $\beta$ mRNA expression had more obvious changes compared to TR $\alpha$ mRNA expression in all these tissues during R. nigromaculata development. The TR $\alpha$ levels in the liver, intestine and tail at stage 42 were approximately 10 times of those at stage 27, while a smaller increase in TR $\alpha$ expression was observed in the brain from stage 27 to stage 42 . However, the TR $\beta$ mRNA levels in the liver, intestine, tail and brain had 205-, 370-, 35- and 19-fold increases from stage 27 to stage 42 , respectively. In terms of the tissue difference, the magnitude of the change in TR $\beta$ expression in the liver was comparable or slightly lower than that in the intestine, which was larger than those in the tail and the brain.

\subsection{Responsiveness of $R$. nigromaculata $T R$ expression to exogenous TR agonist and antagonist}

T3 induced TR $\beta$ mRNA expression in all tissues from stage 27 and 34 tadpoles, but not from stage 42 tadpoles. Moreover, the T3-induced increase in TR $\beta$ expression in stage 27 tadpoles was more dramatic than in stage 34 tadpoles. The observation suggests that the responsiveness of TR $\beta$ expression to T3 is dependent on developmental stage, i.e. the responsiveness decreases with the metamorphic development. At the same developmental stage, T3 had the greatest TR $\beta$ induction in the liver and intestine and the weakest in the brain, showing tissue-specific TR $\beta$ expression, i.e. liver $\approx$ intestine $>$ tail $>$ brain (Fig. 4).

Similarly, $1 \mathrm{nmol} / \mathrm{L}$ T3 did not induce TR $\alpha$ expression in stage 42 tadpoles. In the liver, T3 had a larger TR $\beta$ induction in stage 27 than in 34 tadpoles, whereas no significant difference between stage 27 and stage 34 was observed in both intestine and tail. T3 did not promote TR $\alpha$ expression in the brain at any stage. The observations show that the responsiveness of TR $\alpha$ expression to T3 is also stage-dependent and tissue-specific. In these tissues, T3-induced changes in TR $\alpha$ expression were slight compared to TR $\beta$ expression.

Considering their high responsiveness to $\mathrm{TH}$ and convenience for sampling, we chose intestinal tissues of stage 27 tadpoles as test materials to examine the responsiveness of $R$. nigromaculata to TR antagonists. The tadpoles were exposed to series of concentrations of AM in the presence of $0.1 \mathrm{nmol} / \mathrm{L}$ T3 or in the absence of T3. We found a significant increase (more than 3-fold) of TR $\beta$ expression in the intestine following exposure to T3 compared to the control. AM at the range from 10 to $100 \mathrm{nmol} / \mathrm{L}$ dramatically inhibited T3-induced TR $\beta$ expression, while exposure to AM alone did not affect TR $\beta$ expression (Fig. 5). The result shows that the intestinal tissues of $R$. nigromaculata tadpoles are sensitive to TR antagonists, and TH signaling disrupting effects of TR antagonists could be assayed by evaluating effects of TR antagonists on T3-induced TR $\beta$ expression.

\section{Discussion}

\subsection{Molecular characterization of $\operatorname{TR} \alpha$ and $\operatorname{TR} \beta$ in R. nigromaculata}

Although $R$. nigromaculata has been used in biological and toxicological studies, its TRs have never been molecularly characterized. In this study, we described the cDNA of TR $\alpha$ and TR $\beta$ in R. nigromaculata. TR $\alpha$ consisted of 1760-bp and encoded 418 amino acids, while TR $\beta$ consisted of 1152-bp and encoded 373 amino acids, which accords with molecular characteristics 
Table 2 - Nucleotide and amino acid sequence homology of thyroid hormone receptors (TRs) between Rana nigromaculata and other amphibian species.

$\mathrm{TR} \alpha$

\begin{tabular}{lll}
\cline { 2 - 3 } & Nucleotide & Amino acid \\
\hline Rana catesbeiana & $98 \%$ & $99 \%$ \\
Xenopus laevis TR $\alpha \mathrm{A}$ & $87 \%$ & $98 \%$ \\
Xenopus laevis TR $\alpha \mathrm{B}$ & $87 \%$ & $98 \%$ \\
Xenopus tropicalis & $87 \%$ & $98 \%$ \\
Alligator mississippiensis & $83 \%$ & $94 \%$ \\
Gallus gallus & $82 \%$ & $90 \%$ \\
Equus caballus & $80 \%$ & $84 \%$ \\
Homo sapiens & $80 \%$ & $86 \%$
\end{tabular}

$\operatorname{TR} \beta$

Rana nigromaculata

\begin{tabular}{lll}
\cline { 2 - 3 } & Nucleotide & Amino acid \\
R. catesbeiana & $98 \%$ & $99 \%$ \\
X. laevis TR $\beta$ A & $90 \%$ & $98 \%$ \\
X. laevis TR $\beta$ B & $90 \%$ & $96 \%$ \\
X. tropicalis & $89 \%$ & $98 \%$ \\
X. mississippiensis & $84 \%$ & $95 \%$ \\
G. gallus & $84 \%$ & $95 \%$ \\
E. caballus & $82 \%$ & $95 \%$ \\
H. sapiens & $81 \%$ & $94 \%$
\end{tabular}

of TRs in other amphibian species in the literature. The homologies of nucleotide sequences and deduced amino acid sequences between TR $\alpha$ and TR $\beta$ in R. nigromaculata were $72 \%$ and $86 \%$, respectively. The homology of $\mathrm{TR} \alpha$ to $\mathrm{TR} \beta$ in R. nigromaculata is similar to X. laevis, in which $74 \%$ and $85 \%$ homologies for nucleotide sequences and amino acid sequences were reported between $\mathrm{TR} \alpha$ and $\mathrm{TR} \beta$, respectively (Yaoita et al., 1990).

TR $\alpha$ and TR $\beta$ have been demonstrated to have high homology across vertebrates (Oka et al., 2013). In this study, the amino acid sequence homologies of TR $\alpha$ and TR $\beta$ between R. nigromaculata and X. laevis were approximately $97 \%$ and $98 \%$, respectively. However, TR $\alpha$ and $\mathrm{TR} \beta$ in R. nigromaculata exhibited higher homologies to the corresponding genes in $R$. catesbeiana than in X. laevis, which accords with the fact that R. nigromaculata has a closer evolutionary relationship with R. catesbeiana than with X. laevis (Frost et al., 2006).

\subsection{TR expression patterns during metamorphic development}

In previous studies, TR expression patterns in the intestine, brain, tail and limbs of $\mathrm{X}$. laevis and $\mathrm{X}$. tropicalis during metamorphic development were well characterized (Kawahara et al., 1991; Opitz et al., 2006; Wang et al., 2008; Yaoita and Brown, 1990). However, the data concerning TR expression patterns in the Rana genus has been limited, although Hogan et al. (2007) described TR expression in the brain of $R$. pipiens at four developmental stages. To our knowledge, this is the first detailed description of the developmental expression patterns of TR $\alpha$ and TR $\beta$ in multiple tissues of Rana. We found that the expression patterns of $T R \alpha$ and $T R \beta$ were roughly similar in all examined tissues (liver, intestine, brain and tail) of $R$. nigromaculata tadpoles, i.e. TR expression remained at relatively low levels before stage 40 , followed by an increase and peak at the metamorphic climax (stage 42), and then decreased dramatically or gradually. The developmental expression patterns in $R$. nigromaculata are consistent with previous description for the brain and intestine of X. laevis and X. tropicalis (Yaoita and Brown, 1990; Opitz et al., 2006; Wang et al., 2008). In Xenopus, TR $\alpha$ and TR $\beta$ expression in the brain and intestine peaked at the climax of metamorphosis around stage 61/62 of the Nieuwkoop and Faber system (Nieuwkoop and Faber, 1956), which corresponds to stage 42 according to the Gosner system (Gosner, 1960) in $R$. nigromaculata. In the tail tissue, however, an obvious difference in TR $\alpha$ and TR $\beta$ expression was observed between $R$. nigromaculata and Xenopus. Wang et al. (2008) reported that TR $\alpha$ and $T R \beta$
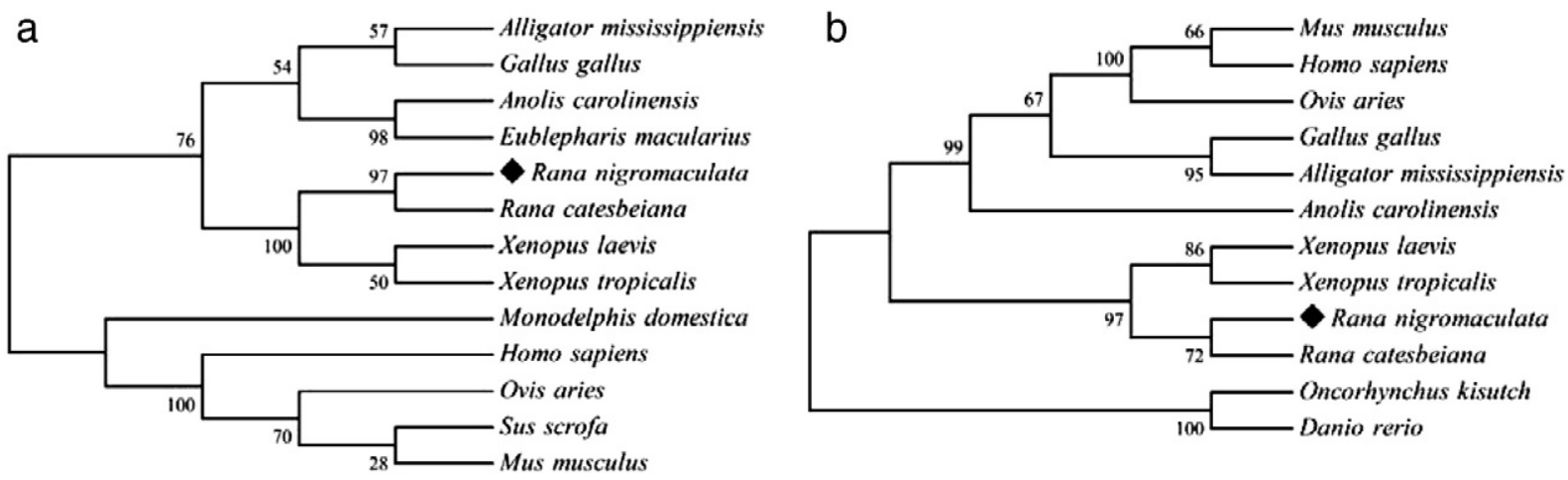

Fig. 2 - Phylogenetic relationships of TRs between Rana nigromaculata and other species. (a) TR $\alpha$, (b) TR $\beta$. The numbers at each branch are the bootstrap values. The relevant amino acid sequences were obtained from the NCBI GenBank database: Alligator mississippiensis (ABD48806.1, ABD48808.1), Gallus gallus (NP_990644.1, NP_990778.1), Anolis carolinensis (XP_003222498.1, XP_003226266.1), Eublepharis macularius (BAF03080.1, BAF03081.1), Rana catesbeiana (Q02777.1, Q02965.1), Xenopus laevis (NP_001081595.1, NP_001090182.1), Xenopus tropicalis (NP_001039261.1, NP_001039270.1), Monodelphis domestica (NP_001184135.1, XP_001369854.1), Homo sapiens (CAA38899.1, NP_000452.2), Sus scrofa (NP_999355.1, XP_001928500.3), Ovis aries (NP_001094389.1, NP_001177320.1), Mus musculus (NP_835161.1, BAE21770.1), Oncorhynchus kisutch (BAE98175.1), and Danio rerio (NP_571415.1). 

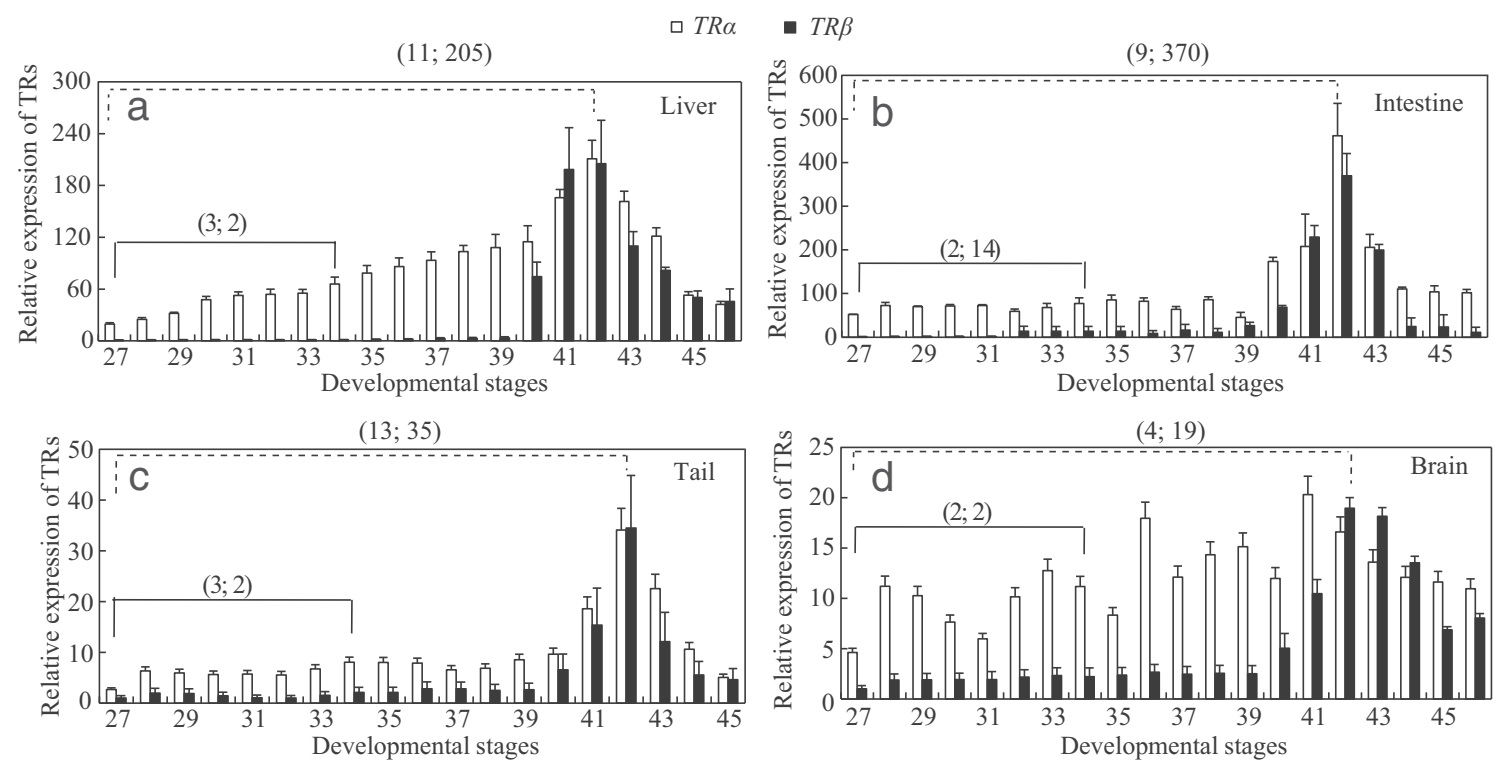

Fig. 3 - Relative expression levels of TRs in different tissues during Rana nigromaculata development. (a) liver, (b) intestine, (c) tail, (d) brain. Relative expression levels of TR $\alpha$ and TR $\beta$ in four tissues were quantified by normalizing to the TR $\beta$ level at stage 27 in the corresponding tissue. Data were shown as means \pm SD (n: 8-10). The numbers on the dotted line (TR $\alpha$; TRß) indicate the fold changes of the TRs expression levels at stage 34 and stage 42 compared to those at stage 27.

expression increased dramatically from stage 58 to stage 64 in X. tropicalis tail. Opitz et al. (2006) also described a continuous increase in TR $\beta$ expression and no change in TR $\alpha$ expression from stage 50 to stage 64 in X. laevis tail. In contrast to Xenopus tail tissue, we found that TR $\alpha$ and TR $\beta$ expression in R. nigromaculata tail reached peak values at stage 42 , followed by a marked decrease to the levels observed before stage 40 . Our finding of the decrease in TR $\alpha$ expression after peaking at Gosner stage 42 in $R$. nigromaculata tail is consistent with a previous report concerning R. catesbeiana (Veldhoen et al., 2006b). In contrast to $T R \alpha$ expression, however, TR $\beta$ expression in $R$. catesbeiana tail tissue was reported to increase continuously after this stage. Tail absorption in Xenopus occurs from NF stage 62 to stage 66, whereas in $R$. nigromaculata and $R$. catesbeiana it occurs from Gosner stage 42 to stage 46 . We cannot explain the biological significance of this species difference in TR expression pattern in the tail tissue.

In spite of a rough similarity in the expression pattern, there were obvious differences in mRNA expression between TR $\alpha$ and TR $\beta$ during $R$. nigromaculata development. In all tissues examined, TR $\beta$ mRNA expression remained at a low level before stage 40 , followed by a dramatic increase and peak at stage 42 , and then decreased. In contrast to TR $\beta$, TR $\alpha$ expression exhibited large differences among these tissues, although TR $\alpha$ expression levels were relatively high in all tissues before stage 40 compared to TR $\beta$. In the brain, $T R \alpha$ expression maintained at a high level during the whole tadpole period, and only exhibited a weak increasing trend from stage 27 to stage $41 / 42$, followed by a slight decrease toward the end of metamorphosis. In the liver, $\mathrm{TR} \alpha$ expression increased progressively from stage 27 to stage 41/42. In the intestine and tail, $T R \alpha$ expression, like $T R \beta$ expression, remained at a low level before stage 40, followed by a dramatic increase and peak at stage 42, and then decreased. To our knowledge, developmental expression patterns of TR in tadpole livers have never been reported in previous studies. It is possible that the developmental expression patterns of TR $\alpha$ in the brain, liver, and intestine/tail represent respectively three typical expression patterns of TR $\alpha$ during R. nigromaculata development. Differences in the developmental expression pattern between TR $\alpha$ and TR $\beta$ were also reported in X. laevis and X. tropicalis (Kawahara et al., 1991; Tata, 2006; Wang et al., 2008; Yaoita and Brown, 1990). In Xenopus, TR $\beta$ expression is believed to be correlated to the $\mathrm{TH}$ levels rather than TR $\alpha$ expression because TR $\beta$ expression parallels the change in the TH level (Kawahara et al., 1991; Yaoita et al., 1990). In a recent study, we described changes in the $\mathrm{TH}$ concentration in R. nigromaculata development, i.e. it maintains at a low level before stage 40 , increases slightly at stage $40 / 41$, followed by a dramatic increase and a peak around stage 42 , and then decreases gradually (Ge et al., 2014). Thus, TR $\beta$ expression in R. nigromaculata, like in Xenopus, is more correlated to the TH levels than TR $\alpha$ expression.

Previous studies have described TR expression patterns in several tissues (including the brain, limb, tail and intestine) during X. laevis and X. tropicalis development (Kawahara et al., 1991; Opitz et al., 2006; Wang et al., 2008; Yaoita and Brown, 1990), but the tissue-specific differences in the magnitude of TR expression change have never been noted, and the relationship between the magnitude of TR expression change and the responsiveness of $\mathrm{TR}$ expression to endogenous $\mathrm{TH}$ has not been discussed. In this study, we observed large tissue differences in the magnitude of the change in TR expression, in particular TR $\beta$ expression, during $R$. nigromaculata development. TR $\beta$ expression exhibited larger changes in the liver and intestine than in the tail and the brain. Considering the correlation of TR expression with $\mathrm{TH}$ levels, we suggest that in terms of TR expression, the intestine and liver might have higher responsiveness to rising $\mathrm{TH}$ levels than the tail and brain. 
Without T3

$1 \mathrm{nmol} / \mathrm{L} \mathrm{T3}$
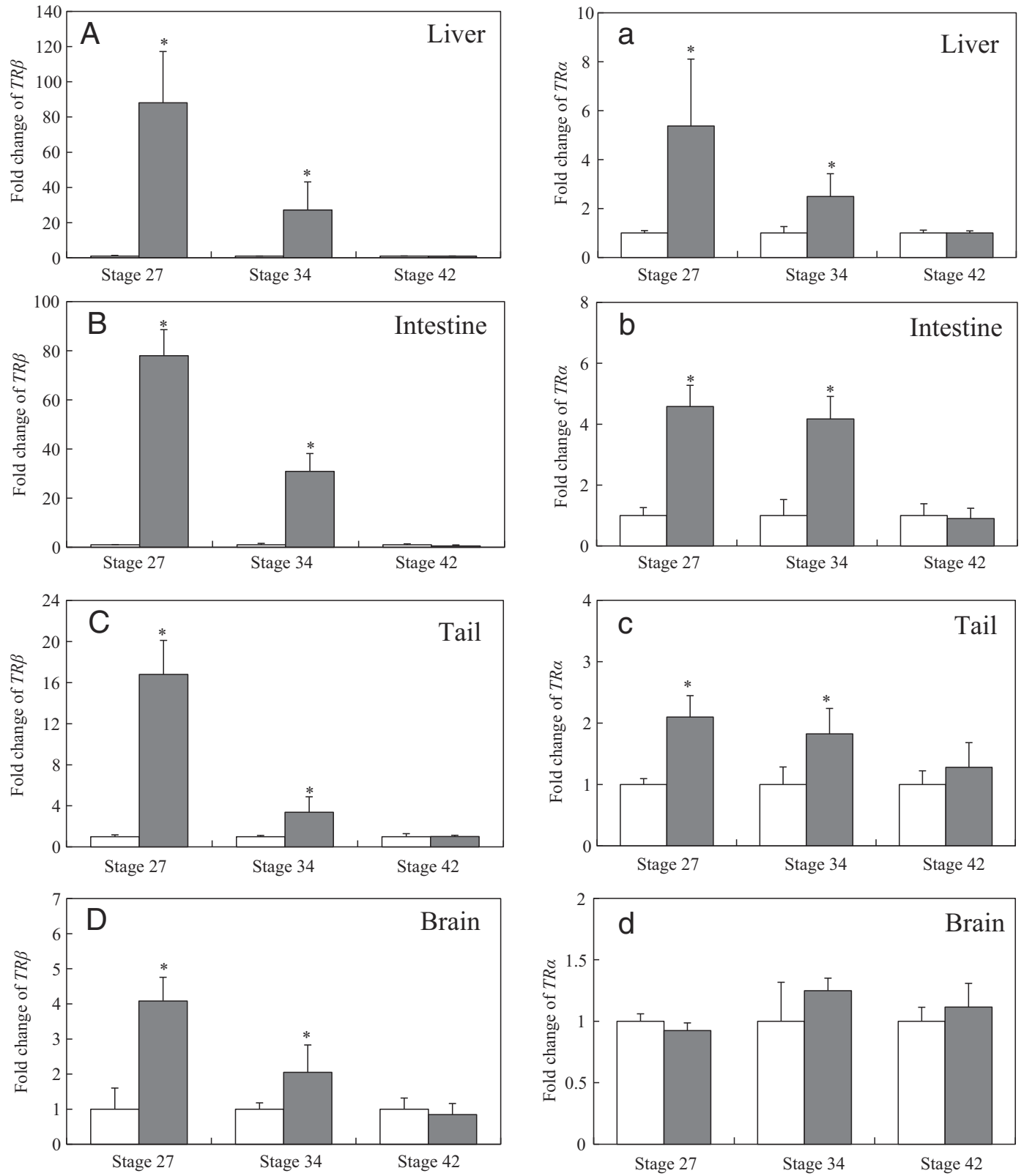

Fig. 4 - Effects of exposure to $1 \mathrm{nmol} / \mathrm{L}$ T3 for $48 \mathrm{hr}$ on TRß and TR $\alpha$ expression in the liver (A, a), intestine (B, b), tail (C, c), and brain (D, d) of $R$. nigromaculata at different stages. Data were shown as means \pm SD ( $n: 10)$. Significant differences between T3 treatment groups and the controls were indicated by * (independent-samples $T$ test, $p<0.05$ ). All experiments were repeated twice with similar results.

\subsection{Responsiveness of TR expression to exogenous TR agonist and antagonist}

$\mathrm{TR} \alpha$ and TR $\beta$ are involved in cell proliferation, differentiation and apoptosis to different degrees. The former is believed to play key roles in establishing tissue competence to respond to THs and in cell proliferation, whereas the latter functions in cell differentiation and apoptosis (Denver et al., 2009; Furlow and Neff, 2006). Expression of TRs (in particular TR $\beta$ ) has been used as a molecular biomarker for assaying $\mathrm{TH}$ signaling disrupting actions in $\mathrm{X}$. laevis because of their response to TH (Opitz et al., 2006; Veldhoen et al., 2006a). To validate $R$. nigromaculata as a native model species for assaying $\mathrm{TH}$ signaling disrupting effects in future study, in this study, we investigated the responsiveness of TR expression to an exogenous TR agonist (T3) and antagonist (AM) in R. nigromaculata tadpoles. In accordance with other amphibian species (Baker and Tata, 1992; Iwamuro et al., 2006; Jagnytsch et al., 2006; Helbing et al., 2006), TR $\beta$ expression had higher responsiveness than TR $\alpha$ expression to $\mathrm{TH}$ in $\mathrm{R}$. nigromaculata tadpoles, showing that 


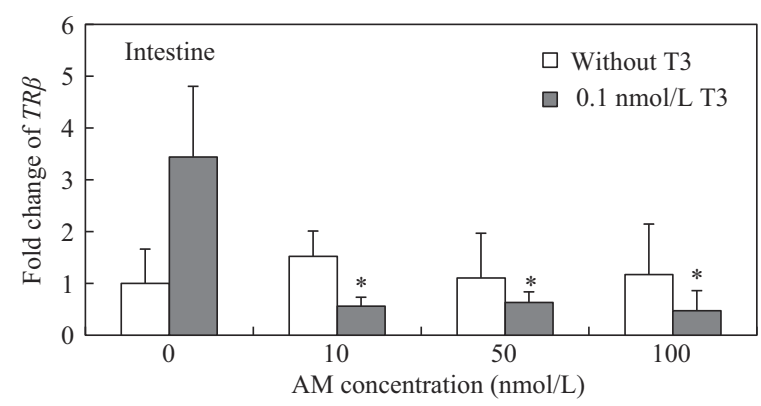

Fig. 5 - Effects of exposure to amiodarone (AM) for $48 \mathrm{hr}$ on TR $\beta$ expression in the presence of $0.1 \mathrm{nmol} / \mathrm{L} \mathrm{T} 3$ or absence of T3 in the intestine at stage 27 Rana nigromaculata. Data were shown as means $\pm \operatorname{SD}(n: 10)$. Significant differences between AM treatment groups and the controls were indicated by * (one-way ANOVA, $p<0.05$ ). All experiments were repeated twice with similar results.

TR $\beta$ expression is a better endpoint than TR $\alpha$ expression for assaying TH signaling disrupting actions.

In addition, it was found that the responsiveness of TR expression to $\mathrm{TH}$ decreased with $\mathrm{R}$. nigromaculata development. TR $\beta$ expression had higher responsiveness to T3 in tadpole tissues at stage 27 than at stage 34 , whereas the response disappeared in the tadpoles at the onset of metamorphic climax. The results are consistent with a previous $X$. laevis study by Opitz et al. (2006), who found that TR expression in head and tail tissues had a high responsiveness to TH in pre-metamorphic tadpoles, whereas the responsiveness decreased in pro-metamorphic tadpoles and strongly diminished in the tadpoles at early metamorphic climax. Opitz et al. (2006) explained that the decreases in the responsiveness to $\mathrm{TH}$ in $\mathrm{X}$. laevis were likely to result from increases in endogenous $\mathrm{TH}$ plasma levels masking the effects of the exogenously added $\mathrm{TH}$ as well as from the increase in basal TR mRNA expression during metamorphic development. Further, we infer that the auto-induction of TR may be regulated by a feedback mechanism. When TR expression levels have peaked in tadpole tissues at stage 42, the tissues will no longer respond to $\mathrm{TH}$ induction. Before the TR levels in tadpole tissues reach the highest values, the tissues will respond to $\mathrm{TH}$ induction according to their needs for TR, i.e. pre-metamorphic tissues with lower TR expression have higher responsiveness, whereas pro-metamorphic tissues with higher TR expression have lower responsiveness. As shown in Fig. 3, both TR $\alpha$ and TR $\beta$ expression levels in all tissues were higher in stage 34 tadpoles than in stage 27 tadpoles. Further studies are needed to clarify the molecular mechanism of developmental stage-dependent responsiveness of TR expression to TH. Considering the responsiveness, R. nigromaculata tadpoles at stage 27 are more suitable than stage 34 tadpoles as test materials for assaying $\mathrm{TH}$ signaling disrupting effects.

In previous studies, tissue-specific responsiveness to $\mathrm{TH}$ was observed in X. laevis (Kawahara et al., 1999; Iwamuro et al., 2003). Kawahara et al. (1999) reported that in terms of TR expression, the intestine was more sensitive to $\mathrm{TH}$ than tail, liver and limb tissues. In this study, we also found tissue-specific responsiveness to TH in R. nigromaculata. At the same developmental stage, the responsiveness of TR $\beta$ expression to $\mathrm{TH}$ ranked in the order of liver $\approx$ intestine $>$ tail $>$ brain (Fig. 4). The order of the responsiveness to TH corresponds to the order of the magnitude of the change in TR expression during $R$. nigromaculata development. In other words, the responsiveness of $\mathrm{TH}$-response genes to exogenous $\mathrm{TH}$ might be coincident with that to endogenous TH. By comparing tissue-specific differences in the responsiveness to $\mathrm{TH}$, we suggest that liver and intestine tissues are more suitable than tail and brain tissues as test materials for in vivo assay of $\mathrm{TH}$ signaling disrupting effects. Certainly, tail tissue can be used in in vitro study due to its advantage of easy culture in vitro (Eto et al., 2012; Tseng et al., 2007). During R. nigromaculata development, the intestine undergoes a dramatic morphological change, but the liver hardly changes in morphology. Moreover, the liver tissues at stage 27 are so small that they are difficult to collect. Thus, the intestines of $R$. nigromaculata are more ideal tissues for assaying TH signaling disrupting effects because their morphological changes could provide more information concerning thyroid disruption.

\section{Conclusions}

R. nigromaculata can be used as a supplement to X. laevis to assay $\mathrm{TH}$ signaling disruption due to its high responsiveness to TR agonist/antagonists and easy accessibility, in particular in East Asia. Given their developmental stage-specific and tissue-specific responsiveness, intestinal tissues of $R$. nigromaculata at stage 27 are ideal test materials for assaying $\mathrm{TH}$ signaling disruption with comprehensive information.

\section{Acknowledgments}

This work was supported by the Public Welfare Research Project for Environmental Protection (No. 201109048), the National High Technology Research and Development Program (863) of China (No. 2012AA06A302), and the National Natural Science Foundation of China (No. 21077125).

\section{R E F E R E N C E S}

Arukwe, A., Jenssen, B.M., 2005. Differential organ expression patterns of thyroid hormone receptor isoform genes in $\mathrm{p}$, p'-DDE-treated adult male common frog, Rana temporaria. Environ. Toxicol. Pharmacol. 20 (3), 485-492.

Baker, B.S., Tata, J.R., 1992. Prolactin prevents the autoinduction of thyroid hormone receptor mRNAs during amphibian metamorphosis. Dev. Biol. 149 (2), 463-467.

Bernal, J., Guadano-Ferraz, A., Morte, B., 2003. Perspectives in the study of thyroid hormone action on brain development and function. Thyroid 13 (11), 1005-1012.

Brucker-Davis, F., 1998. Effects of environmental synthetic chemicals on thyroid function. Thyroid 8 (9), 827-856.

Carr, J.A., Patino, R., 2011. The hypothalamus-pituitary-thyroid axis in teleosts and amphibians: endocrine disruption and its consequences to natural populations. Gen. Comp. Endocrinol. 170 (2), 299-312. 
Croteau, M.C., Davidson, M., Duarte-Guterman, P., Wade, M., Popesku, J.T., Wiens, S., et al., 2009. Assessment of thyroid system disruption in Rana pipiens tadpoles chronically exposed to UVB radiation and 4-tert-octylphenol. Aquat. Toxicol. 95 (2), 81-92.

Das, B., Matsuda, H., Fujimoto, K., Sun, G.H., Matsuura, K., Shi, Y.B., 2010. Molecular and genetic studies suggest that thyroid hormone receptor is both necessary and sufficient to mediate the developmental effects of thyroid hormone. Gen. Comp. Endocrinol. 168 (2), 174-180.

Degitz, S.J., Holcombe, G.W., Flynn, K.M., Kosian, P.A., Korte, J.J., Tietge, J.E., 2005. Progress towards development of an amphibian-based thyroid screening assay using Xenopus laevis. Organismal and thyroidal responses to the model compounds 6-propylthiouracil, methimazole, and thyroxine. Toxicol. Sci. 87 (2), 353-364.

Denver, R.J., Hu, F., Scanlan, T.S., Furlow, J.D., 2009. Thyroid hormone receptor subtype specificity for hormone-dependent neurogenesis in Xenopus laevis. Dev. Biol. 326 (1), 155-168.

Eto, K., Iwama, T., Tajima, T., Abe, S.I., 2012. The RNA-binding protein XCIRP2 is involved in apoptotic tail regression during metamorphosis in Xenopus laevis tadpoles. Gen. Comp. Endocrinol. 179 (1), 14-21.

Fini, J.B., Le Mevel, S., Palmier, K., Darras, V.M., Punzon, I., Richardson, S.J., et al., 2012. Thyroid hormone signaling in the Xenopus laevis embryo is functional and susceptible to endocrine disruption. Endocrinology 153 (10), 5068-5081.

Frost, D.R., Grant, T., Faivovich, J., Bain, R.H., Haas, A., Haddad, C.F., et al., 2006. The amphibian tree of life. Bulletin of the American Museum of Natural History. American Museum of Natural History, New York, pp. 1-291.

Furlow, J.D., Neff, E.S., 2006. A developmental switch induced by thyroid hormone Xenopus laevis metamorphosis. Trends Endocrinol. Metab. 17 (2), 40-47.

Ge, Y.N., Li, Y.Y., Zhang, Y.F., Lou, Q.Q., Zhao, Y.X., Qin, Z.F., 2014. Thyroid gland development and thyroid hormone levels during Rana nigromaculata metamorphosis. Acta Hydrobiol. Sin. 38 (4), 714-719.

Gosner, K.L., 1960. A simplified table for staging anuran embryos and larvae with notes on identification. Herpetologica 16 (3), 183-190.

Gutleb, A.C., Appelman, J., Bronkhorst, M., Van Den Berg, J.H., Murk, A.J., 2000. Effects of oral exposure to polychlorinated biphenyls (PCBs) on the development and metamorphosis of two amphibian species (Xenopus laevis and Rana temporaria). Sci. Total Environ. 262 (1), 147-157.

Gutleb, A.C., Schriks, M., Mossink, L., Van Den Berg, J.H.J., Murk, A.J., 2007. A synchronized amphibian metamorphosis assay as an improved tool to detect thyroid hormone disturbance by endocrine disruptors and apolar sediment extracts. Chemosphere 70 (1), 93-100.

Hanada, H., Katsu, K., Kanno, T., Sato, E.F., Kashiwagi, A., Sasaki, J., et al., 2003. Cyclosporin A inhibits thyroid hormone-induced shortening of the tadpole tail through membrane permeability transition. Comp. Biochem. Physiol. B Biochem. Mol. Biol. 135 (3), 473-483.

Heimeier, R.A., Das, B., Buchholz, D.R., Shi, Y.B., 2009. The xenoestrogen bisphenol A inhibits postembryonic vertebrate development by antagonizing gene regulation by thyroid hormone. Endocrinology 150 (6), 2964-2973.

Heimeier, R.A., Das, B., Buchholz, D.R., Fiorentino, M., Shi, Y.B., 2010. Studies on Xenopus laevis intestine reveal biological pathways underlying vertebrate gut adaptation from embryo to adult. Genome Biol. 11 (5), R55.

Helbing, C.C., Ovaska, K., Ji, L., 2006. Evaluation of the effect of acetochlor on thyroid hormone receptor gene expression in the brain and behavior of Rana catesbeiana tadpoles. Aquat. Toxicol. 80 (1), 42-51.

Hogan, N.S., Crump, K.L., Duarte, P., Lean, D.R.S., Trudeau, V.L., 2007. Hormone cross-regulation in the tadpole brain: developmental expression profiles and effect of T3 exposure on thyroid hormone-and estrogen-responsive genes in Rana pipiens. Gen. Comp. Endocrinol. 154 (1-3), 5-15.

Iwamuro, S., Sakakibara, M., Terao, M., Ozawa, A., Kurobe, C., Shigeura, T., et al., 2003. Teratogenic and anti-metamorphic effects of bisphenol A on embryonic and larval Xenopus laevis. Gen. Comp. Endocrinol. 133 (2), 189-198.

Iwamuro, S., Yamada, M., Kato, M., Kikuyama, S., 2006. Effects of bisphenol A on thyroid hormone-dependent up-regulation of thyroid hormone receptor alpha and beta and down-regulation of retinoid $\mathrm{X}$ receptor gamma in Xenopus tail culture. Life Sci. 79 (23), 2165-2171.

Jagnytsch, O., Opitz, R., Lutz, I., Kloas, W., 2006. Effects of tetrabromobisphenol A on larval development and thyroid hormone-regulated biomarkers of the amphibian Xenopus laevis. Environ. Res. 101 (3), 340-348.

Kawahara, A., Baker, B.S., Tata, J.R., 1991. Developmental and regional expression of thyroid hormone receptor genes during Xenopus metamorphosis. Development 112, 933-943.

Kawahara, A., Gohda, Y., Hikosaka, A., 1999. Role of type III iodothyronine 5-deiodinase gene expression in temporal regulation of Xenopus metamorphosis. Develop. Growth Differ. 41 (3), 365-373.

Langer, P., Kocan, A., Tajtakova, M., Petrik, J., Chovancova, J., Drobna, B., et al., 2007. Fish from industrially polluted freshwater as the main source of organochlorinated pollutants and increased frequency of thyroid disorders and dysglycemia. Chemosphere 67 (9), S379-S385.

Li, X.Y., Zhou, J., Yu, M., Wang, J.J., Pei, Y.C., 2009. Toxic effects of 1-methyl-3-octylimidazolium bromide on the early embryonic development of the frog Rana nigromaculata. Ecotoxicol. Environ. Saf. 72 (2), 552-556.

Lou, Q.Q., Cao, S., Xu, W., Zhang, Y.F., Qin, Z.F., Wei, W.J., 2014. Molecular characterization and mRNA expression of ribosomal protein L8 in Rana nigromaculata during development and under exposure to hormones. J. Environ. Sci. 26 (11) (In press).

Nieuwkoop, P.D., Faber, J., 1956. Normal Table of Xenopus Laevis (Daudin). A Systematical and Chronological Survey of the Development From the Fertilized Egg Till the End of Metamorphosis. Garland Publishing Inc., p. 22.

Oka, T., Miyahara, M., Yamamoto, J., Mitsui, N., Fujii, T., Tooi, O., et al., 2009. Application of metamorphosis assay to a native Japanese amphibian species, Rana rugosa, for assessing effects of thyroid system affecting chemicals. Ecotoxicol. Environ. Saf. 72 (5), 1400-1405.

Oka, T., Mitsui Watanabe, N., Tatarazako, N., Onishi, Y., Katsu, Y., Miyagawa, S., et al., 2013. Establishment of transactivation assay systems using fish, amphibian, reptilian and human thyroid hormone receptors. J. Appl. Toxicol. 33 (9), 991-1000.

Opitz, R., Lutz, I., Nguyen, N.H., Scanlan, T.S., Kloas, W., 2006. Analysis of thyroid hormone receptor $\beta$ A mRNA expression in Xenopus laevis tadpoles as a means to detect agonism and antagonism of thyroid hormone action. Toxicol. Appl. Pharmacol. 212 (1), 1-13.

Park, S., Park, S.H., Ahn, H.C., Kim, S., Kim, S.S., Lee, B.J., 2001. Structural study of novel antimicrobial peptides, nigrocins, isolated from Rana nigromaculata. FEBS Lett. 507 (1), 95-100.

State Science, Technology Commission in China, 1988. Regulation for the administration of affairs concerning experimental animals. The Ministry of Science and Technology of the People's Republic of China, Beijing.

Sumida, M., Kanamori, Y., Kaneda, H., Kato, Y., Nishioka, M., Hasegawa, M., et al., 2001. Complete nucleotide sequence and gene rearrangement of the mitochondrial genome of the Japanese pond frog Rana nigromaculata. Genes Genet. Syst. 76 (5), 311-325.

Sumida, M., Kato, Y., Kurabayashi, A., 2004. Sequencing and analysis of the internal transcribed spacers (ITSs) and coding 
regions in the EcoR I fragment of the ribosomal DNA of the Japanese pond frog Rana nigromaculata. Genes Genet. Syst. 79 (2), 105-118.

Takase, M., Ukena, K., Tsutsui, K., 2002. Expression and localization of cytochrome P450(11beta,aldo) mRNA in the frog brain. Brain Res. 950 (1-2), 288-296.

Tata, J.R., 2006. Amphibian metamorphosis as a model for the developmental actions of thyroid hormone. Mol. Cell. Endocrinol. 246 (1-2), 10-20.

Tseng, A.S., Adams, D.S., Qiu, D., Koustubhan, P., Levin, M., 2007. Apoptosis is required during early stages of tail regeneration in Xenopus laevis. Dev. Biol. 301 (1), 62-69.

Veldhoen, N., Skirrow, R.C., Osachoff, H., Wigmore, H., Clapson, D.J., Gunderson, M.P., et al., 2006a. The bactericidal agent triclosan modulates thyroid hormone-associated gene expression and disrupts postembryonic anuran development. Aquat. Toxicol. 80 (3), 217-227.

Veldhoen, N., Skirrow, R.C., Ji, L., Domanski, D., Bonfield, E.R., Bailey, C.M., et al., 2006b. Use of heterologous cDNA arrays and organ culture in the detection of thyroid hormone-dependent responses in a sentinel frog, Rana catesbeiana. Comp. Biochem. Physiol. D: Genomics Proteomics 1 (2), 187-199.

Wang, M.Z., Jia, X.Y., 2009. Low levels of lead exposure induce oxidative damage and DNA damage in the testes of the frog Rana nigromaculata. Ecotoxicology 18 (1), 94-99.

Wang, X.D., Matsuda, H., Shi, Y.B., 2008. Developmental regulation and function of thyroid hormone receptors and 9-cis retinoic acid receptors during Xenopus tropicalis metamorphosis. Endocrinology 149 (11), 5610-5618.

Yaoita, Y., Brown, D.D., 1990. A correlation of thyroid-hormone receptor gene-expression with amphibian metamorphosis. Genes Dev. 4 (11), 1917-1924.

Yaoita, Y., Shi, Y.B., Brown, D.D., 1990. Xenopus laevis alpha and beta thyroid hormone receptors. Proc. Natl. Acad. Sci. U. S. A. 87 (18), 7090-7094.

Yen, P.M., 2001. Physiological and molecular basis of thyroid hormone action. Physiol. Rev. 81 (3), 1097-1142.

Zoeller, R.T., 2007. Environmental chemicals impacting the thyroid: targets and consequences. Thyroid 17 (9), 811-817. 